\title{
INDICADORES DAS CONDIÇÕES NUTRICIONAIS NA REGIÃO DO POLONOROESTE. IV. INQUÉRITO ALIMENTAR EM FAMÍLIAS DE SEIS CIDAdES dA REGIÃO dO POLONOROESTE, MATO GROSSO, BRASIL, 1983
}

R.R. da SILVA (1), M.A. dos SANTOS SPINELLI (1) M.C.W. ALBUQUERQUE (1), S.M.C. dos SANTOS (1) \& E.M. YOKOO (2)

\begin{abstract}
RESUMO
O trabalho se refere aos dados coletados em inquérito alimentar recordatório de 24 h no Inquérito Nutricional da Pesquisa Diagnóstico em Saúde no Polonoroeste em 1983 em 6 cidades da regiào do Polonoroeste/MT. Como uma primeira aproximação da problemática alimentar da região, o estudo revela os alimentos mais referidos nas entrevistas que são alimentos básicos, fontes de energia, semiindustrializados e de custo mais baixo.
\end{abstract}

UNITERMOS: Inquérito alimentar.

\section{INTRODUÇÃO}

Este trabalho é parte da pesquisa Inquérito Nutricional do Diagnóstico em Saúde no Polonoroeste, etapa de 1983.

O objetivo do Inquérito Nutricional é fornecer elementos para o diagnóstico das condiçōes de alimentação e nutrição na região enfocada, assim, compõe-se de 3 partes: estudo clínico-antropométrico, estudo do consumo de alimentos e das características sócioeconômicas das famílias em estudo.

O estudo sobre o consumo de alimentos de que trata este artigo, teve como objetivo o reconhecimento do universo alimentar das famílias, isto é, dos alimentos que habitualmente fazem parte das suas refeições diárias.

Os levantamentos que utilizam o método recordatório de 24 horas questionando o entre- vistado sobre a alimentação consumida no dia anterior têm sido os mais utilizados e conferem ao estudo certo grau de confiabilidade, principalmente quando investigam um grande número de famílias.

Devido às características organizacionais da pesquisa, foi proposto um estudo qualitativo dos alimentos ingeridos. Assim sendo, pode-se considerar este estudo como uma primeira aproximação da problemática alimentar da região.

\section{MATERIAL E MÉTODOS}

Foram entrevistadas $50 \%$ das famílias selecionadas para compor a amostra da Pesquisa

(1) Professor-Assistente do Departamento de Nutriçāo - UFMT. Pesquisadora do Grupo de Inquérito Nutricional - Polonoroeste.

(2) Nutricionista-Bolsista da Pesquisa Inquérito Nutricional -- Polonoroeste.

Endereço para correspondência: Universidade Federal de Mato Grosso - Av. Fernando Corrêa, s/n' - 78100 Cuiabá, Ma10 Cirosso, Brasil. 
SILVA, R.R. da; SANTOS SPINELLI, M.A. dos; ALBUQUERQUE, M.C.W.: SANTOS, S.M.C. dos \& YOKOO, E. M. - Indicadores das condiçós nutricionais na Região do Polonoroeste. IV. Inquerito alimentar em famílias de seis cidades da Regiào do Polonoroeste, Mato Grosso, Brasil, 1983. Rev. Inst. Med. trop. São Paulo, 30(3):185-191, 1988.

Inquérito Epidemiológico por Entrevistas Domiciliares, num total de 575, residentes nas áreas urbanas dos municípios de Jaurú, Araputanga, Mirassol D’Oeste, Cáceres, Tangará da Serra e do distrito de Nova Olimpia, durante os meses de setembro a dezembro de 1983. O desenho amostral e a escolha das cidades obedecem o modelo proposto por MEIRELLESı para o desenvolvimento da Pesquisa Diagnóstico em Saúde no Polonoroeste.

Foi aplicado um formulário que, além de um inquérito alimentar recordatório de $24 \mathrm{~h}$ de natureza qualitativa, procurou obter dados sobre a forma de aquisição dos gêneros alimenticios, as refeições realizadas fora do domicílio pelos membros da família e características da alimentação de uma criança de até 24 meses de idade. Quando ocorria de existir mais de uma criança nesta faixa etária num mesmo domicílio, uma das crianças era sorteada para compor o estudo.

As entrevistas foram realizadas pelos entrevistadores da Pesquisa Inquérito Epidemiológico por Entrevistas Domiciliares.
No tratamento estatístico dos dados, estes foram considerados representativos apenas do grupo estudado.

Neste trabalho são apresentados apenas os dados obtidos no inquérito recordatório de 24 horas do consumo alimentar.

A tabela 1 apresenta o número de familias entrevistadas em cada cidade incluida na pesquisa.

TABELA 1

Famílias estudadas através do inquérito alimentar Polonoroeste -1983 .

\begin{tabular}{lrr}
\hline Cidade & No & $\%$ \\
\hline Jauru & 24 & 4,0 \\
Araputanga & 68 & 12,0 \\
Mirassol D'Oeste & 154 & 27,0 \\
Cáceres & 223 & 39,0 \\
Tangará da Serra & 60 & 10,0 \\
Nova Olímpia & 46 & 8,0 \\
\hline TOTAL & 573 & 100,0 \\
\hline
\end{tabular}

TABELA 2

Referência ao consumo de Cereais e Derivados: percentual médio em cada cidade e na região - 1983.

\begin{tabular}{|c|c|c|c|c|c|c|c|}
\hline Alimento & $\begin{array}{c}\text { Jauru } \\
\%\end{array}$ & $\begin{array}{c}\text { Araputanga } \\
\%\end{array}$ & $\begin{array}{c}\text { Mirassol } \\
\text { D'Oeste } \\
\%\end{array}$ & $\begin{array}{c}\text { Cáceres } \\
\%\end{array}$ & $\begin{array}{c}\text { Tangará } \\
\text { da Serra } \\
\%\end{array}$ & $\begin{array}{c}\text { Nova } \\
\text { Olímpia } \\
\%\end{array}$ & $\begin{array}{c}\text { Médio } \\
\text { Região } \\
\%\end{array}$ \\
\hline Arroz & 94,5 & 91,5 & 99,0 & 88,0 & 96,0 & 98,0 & 99,5 \\
\hline Pão & 32,0 & 54,0 & 46,0 & 70,0 & 68,0 & 47,0 & 53,0 \\
\hline Macarrão & 24,0 & 23,5 & 19,0 & 21,0 & 33,0 & 22,5 & 24,0 \\
\hline Farinha Trigo & 3,0 & 13,0 & 8,0 & 21,0 & 4,0 & 11,0 & 10,0 \\
\hline Outros & 13,5 & 1,0 & 2,0 & 3,5 & 1,0 & - & 3,5 \\
\hline
\end{tabular}

TABELA 3

Referência ao Consumo de Leguminosa; percentual médio em cada cidade e na Região - 1983.

\begin{tabular}{|c|c|c|c|c|c|c|c|}
\hline Alimento & $\begin{array}{c}\text { Jauru } \\
\%\end{array}$ & $\begin{array}{c}\text { Araputanga } \\
\%\end{array}$ & $\begin{array}{c}\text { Mirassol } \\
\text { D'Oeste } \\
\%\end{array}$ & $\begin{array}{c}\text { Cáceres } \\
\%\end{array}$ & $\begin{array}{c}\text { Tangará } \\
\text { da Serra } \\
\%\end{array}$ & $\begin{array}{c}\text { Nova } \\
\text { Olímpia } \\
\%\end{array}$ & $\begin{array}{c}\text { Médio } \\
\text { Região } \\
\%\end{array}$ \\
\hline $\begin{array}{l}\text { Feijão } \\
\text { Outros }\end{array}$ & $\begin{array}{c}97,0 \\
-\end{array}$ & 94,5 & 96,0 & 79,5 & 92,0 & 94,0 & 92,0 \\
\hline
\end{tabular}


SILVA, R.R. da; SANTOS SPINELLI, M.A. dos; ALBUQUERQUE, M.C.W.; SANTOS, S.M.C. dos \& YOKOO, E. M. - Indicadores das condições nutricionais na Regiào do Polonoroeste. IV. Inquérito alimentar em familias de seis cidades da Regiāo do Polonoroeste, Mato Grosso, Brasil, 1983. Rev. Inst. Med. trop. São Paulo, 30(3):185-191, 1988.

TABELA 4

Referência ao consumo de Raízes, Tubérculos e Derivados: percentual médio em cada cidade e região - 1983.

\begin{tabular}{|c|c|c|c|c|c|c|c|}
\hline Alimento & $\begin{array}{c}\text { Jauru } \\
\%\end{array}$ & $\begin{array}{c}\text { Araputanga } \\
\%\end{array}$ & $\begin{array}{c}\text { Mirassol } \\
\text { D'Oeste } \\
\%\end{array}$ & $\begin{array}{c}\text { Cáceres } \\
\%\end{array}$ & $\begin{array}{c}\text { Tangará } \\
\text { da Serra } \\
\%\end{array}$ & $\begin{array}{c}\text { Nova } \\
\text { Olímpia } \\
\%\end{array}$ & $\begin{array}{c}\text { Médio } \\
\text { Regiāo } \\
\%\end{array}$ \\
\hline Batata Inglesa & 3,0 & $1 i, 0$ & 9,0 & 21,5 & 13,5 & 15,0 & 12,0 \\
\hline Farinha Mandioca & 16,0 & 6,5 & 5,0 & 11,5 & 4,0 & 5,5 & 8,0 \\
\hline Mandioca & 5,5 & 1,0 & 4,5 & 11,5 & 4,0 & 5,5 & 5,5 \\
\hline Outros & 5,5 & 4,5 & 4,5 & - & 1,0 & - & 2,5 \\
\hline
\end{tabular}

TABELA 5

Referência ao consumo de Carnes e Derivados : percentual médio em cada cidade e na região - 1983.

\begin{tabular}{|c|c|c|c|c|c|c|c|}
\hline Alimento & $\begin{array}{c}\text { Jauru } \\
\%\end{array}$ & $\begin{array}{c}\text { Araputanga } \\
\%\end{array}$ & $\begin{array}{c}\text { Mirassol } \\
\text { D'Oeste } \\
\%\end{array}$ & $\begin{array}{c}\text { Cáceres } \\
\%\end{array}$ & $\begin{array}{c}\text { Tangará } \\
\text { da Serra } \\
\%\end{array}$ & $\begin{array}{c}\text { Nova } \\
\text { Olímpia } \\
\%\end{array}$ & $\begin{array}{c}\text { Médio } \\
\text { Região } \\
\text { \% }\end{array}$ \\
\hline Carne Boi & 30,0 & 64,5 & 38,0 & 60,0 & 49,5 & 53,0 & 49,0 \\
\hline Peixe & 5,5 & 9,5 & 10,5 & 14,5 & 9,0 & 11,0 & 10,0 \\
\hline Frango & 8,0 & 5,0 & 10,5 & 12,5 & 9,0 & 7,5 & 8,5 \\
\hline Carne Porco & 5,0 & 8,5 & 8,0 & 1,5 & 8,0 & - & 5,0 \\
\hline Lingüiça & - & 5,0 & 2,0 & 2,0 & 1,0 & - & 1,5 \\
\hline Outros & 3,0 & 11,0 & 6,0 & 5,5 & 9,0 & 1,0 & 6,0 \\
\hline
\end{tabular}

TABELA 6

Referência ao consumo de Leite, Derivados e Ovos: percentual médio em cada cidade e na região - 1983.

\begin{tabular}{|c|c|c|c|c|c|c|c|}
\hline Alimento & $\begin{array}{c}\text { Jauru } \\
\%\end{array}$ & $\begin{array}{c}\text { Araputanga } \\
\%\end{array}$ & $\begin{array}{c}\text { Mirassol } \\
\text { D'Oeste } \\
\%\end{array}$ & $\begin{array}{c}\text { Cáceres } \\
\text { \% }\end{array}$ & $\begin{array}{c}\text { Tangará } \\
\text { da Serra } \\
\%\end{array}$ & $\begin{array}{c}\text { Nova } \\
\text { Olímpia } \\
\%\end{array}$ & $\begin{array}{c}\text { Médio } \\
\text { Região } \\
\%\end{array}$ \\
\hline Leite de Vaca & & & & & & & \\
\hline "In Natura" & 20,0 & 47,0 & 25,5 & 35,0 & 31,0 & 28,0 & 31,0 \\
\hline Ovos & 27,0 & 29,0 & 21,0 & 27,0 & 22,5 & 21,0 & 24,5 \\
\hline Queijo & - & 5,0 & 3,0 & 6,0 & 8,0 & 2,0 & 4,0 \\
\hline $\begin{array}{l}\text { Outros derivados } \\
\text { do leite }\end{array}$ & - & 2,0 & 1,0 & 1,0 & - & 2,0 & 1,0 \\
\hline
\end{tabular}

TABELA 7

Referência ao consumo de Óleos e Gorduras: percentual médio em cada cidade e na região - 1983.

\begin{tabular}{|c|c|c|c|c|c|c|c|}
\hline Alimento & $\begin{array}{c}\text { Jauru } \\
\%\end{array}$ & $\begin{array}{c}\text { Araputanga } \\
\%\end{array}$ & $\begin{array}{c}\text { Mirassol } \\
\text { D'Oeste } \\
\%\end{array}$ & $\begin{array}{c}\text { Cáceres } \\
\%\end{array}$ & $\begin{array}{c}\text { Tangará } \\
\text { da Serra } \\
\%\end{array}$ & $\begin{array}{c}\text { Nova } \\
\text { Olímpia } \\
\%\end{array}$ & $\begin{array}{l}\text { Médio } \\
\text { Região } \\
\quad \%\end{array}$ \\
\hline Oleo Vegetal & 78,0 & 75,0 & 75,0 & 81,0 & 81,0 & 78,5 & - \\
\hline Manteiga & 8,0 & 29,0 & 22,5 & 40,0 & 19,5 & 13,0 & 22,0 \\
\hline Banha & 27,0 & 14,0 & 22,0 & 5,0 & 15,5 & 15,0 & 16,5 \\
\hline Margarina & 3,0 & 3,0 & 4,0 & 4,5 & 20,5 & 9,5 & 7,5 \\
\hline Azeite Oliva & - & - & 2,0 & - & 1,0 & 2,0 & 0,8 \\
\hline
\end{tabular}


SILVA, R.R. da; SANTOS SPINELLI, M.A. dos; ALBUQUERQUE, M.C.W.; SANTOS, S.M.C. dos \& YOKOO, E.M. - Indicadores das condições nutricionais na Região do Polonoroeste. IV. Inquérito alimentar em familias de seis cidades da Região do Polonoroeste, Mato Grosso, Brasil, 1983. Rev. Inst. Med. trop. São Paulo, 30(3):185-191, 1988.

TABELA 8

Referência ao consumo de Açúcares: percentual médio em cada cidade e na Região - 1983.

\begin{tabular}{|c|c|c|c|c|c|c|c|}
\hline Alimento & $\begin{array}{c}\text { Jauru } \\
\%\end{array}$ & $\begin{array}{c}\text { Araputanga } \\
\%\end{array}$ & $\begin{array}{c}\text { Mirassol } \\
\text { D'Oeste } \\
\%\end{array}$ & $\begin{array}{c}\text { Cáceres } \\
\%\end{array}$ & $\begin{array}{c}\text { Tangará } \\
\text { da Serra } \\
\%\end{array}$ & $\begin{array}{c}\text { Nova } \\
\text { Olímpia } \\
\%\end{array}$ & $\begin{array}{c}\text { Médio } \\
\text { Região }\end{array}$ \\
\hline Açúcar & $\begin{array}{c}89,0 \\
-\end{array}$ & $\begin{array}{r}85,0 \\
50\end{array}$ & $\begin{array}{r}89,0 \\
20\end{array}$ & $\begin{array}{r}81,0 \\
25\end{array}$ & $\begin{array}{r}96,0 \\
80\end{array}$ & 81,0 & 87,0 \\
\hline
\end{tabular}

TABELA 9

Referência ao Consumo de Hortaliças: Percentual médio em cada cidade e Região - 1983.

\begin{tabular}{|c|c|c|c|c|c|c|c|}
\hline Hortaliça & $\begin{array}{c}\text { Jauru } \\
\%\end{array}$ & $\begin{array}{c}\text { Araputanga } \\
\%\end{array}$ & $\begin{array}{c}\text { Mirassol } \\
\text { D’Oeste } \\
\%\end{array}$ & $\begin{array}{c}\text { Cáceres } \\
\%\end{array}$ & $\begin{array}{c}\text { Tangará } \\
\text { da Serra } \\
\%\end{array}$ & $\begin{array}{l}\text { Nova } \\
\text { Olímpia } \\
\%\end{array}$ & $\begin{array}{c}\text { Médio } \\
\text { Região } \\
\%\end{array}$ \\
\hline 1. Cebola & 32,5 & 55,0 & 53,0 & 53,0 & 51,5 & 49,0 & 49,0 \\
\hline 2. Tomate & 27,0 & 54,0 & 33,5 & 35,0 & 32,0 & 36,0 & 36,0 \\
\hline 3. Alface & 24,0 & 50,5 & 22,0 & 18,5 & 9,0 & 2,0 & 21,0 \\
\hline 4. Couve & 11,0 & 9,5 & 7,5 & 11,0 & 1,0 & - & 6,5 \\
\hline 5. Repolho & 8,0 & 13,0 & 7,5 & 8,0 & 6,0 & 5,5 & 8,0 \\
\hline 6. Pimentâo & 11,0 & 4,0 & 3,0 & 5,0 & 10,0 & 9,5 & 7,0 \\
\hline 7. Pepino & - & 9,5 & 6,0 & 3,0 & 7,0 & 9,5 & 6,0 \\
\hline 8. Cenoura & 3,0 & 5,0 & 0,5 & 8,5 & 4,0 & 2,0 & 4,0 \\
\hline 9. Quiabo & - & - & 2,0 & 2,0 & 8,0 & 19,0 & 5,0 \\
\hline 10. Abóbora & 3,0 & 1,0 & 1,0 & 3,0 & 2,0 & 15,0 & 4,0 \\
\hline 11. Almeirão & 3,0 & 1,0 & 4,0 & 1,0 & 8,0 & - & 3,0 \\
\hline 12. Chuchu & - & 2,0 & 1,0 & 3,0 & 3,0 & 6,6 & 2,5 \\
\hline 13. Abobrinha & 3,0 & 2,0 & 2,0 & - & 4,0 & 4,0 & 2,5 \\
\hline 14. Beterraba & 3,0 & 2,0 & - & 2,0 & - & - & 1,0 \\
\hline 15. Maxixe & - & - & - & - & - & 7,5 & 1,0 \\
\hline 16. Chicória & - & 1,0 & 0,5 & - & - & 2,0 & 0,5 \\
\hline 17. Jiló & - & - & 0,5 & 0,5 & - & - & 2,0 \\
\hline 18. Rúcula & - & _- & 1,0 & - & - & - & 0,2 \\
\hline 19. Mostarda & - & - & - & 0,5 & - & - & 0,1 \\
\hline 20. Beringela & 5,0 & - & - & - & - & - & 1,0 \\
\hline 21. Beringela & - & 1,0 & - & - & - & - & 0,2 \\
\hline 22. Nabo & - & 1,0 & - & - & - & - & 0,2 \\
\hline 23. Vagem & - & - & - & - & 2,0 & - & 0,3 \\
\hline 24. Gariroba & - & 1,0 & - & - & - & - & 0,2 \\
\hline
\end{tabular}

TABELA 10

Referência ao consumo de Frutas: percentual médio em cada cidade e na região - 1983.

\begin{tabular}{|c|c|c|c|c|c|c|c|}
\hline Frutas & $\begin{array}{c}\text { Jauru } \\
\%\end{array}$ & $\begin{array}{c}\text { Araputanga } \\
\%\end{array}$ & $\begin{array}{c}\text { Mirassol } \\
\text { D'Oeste } \\
\%\end{array}$ & $\begin{array}{c}\text { Cáceres } \\
\%\end{array}$ & $\begin{array}{c}\text { Tangará } \\
\text { da Serra } \\
\%\end{array}$ & $\underset{\%}{\text { Nova }}$ & $\begin{array}{c}\text { Médio } \\
\text { Região } \\
\%\end{array}$ \\
\hline Banana & 11,0 & 3,0 & 4,5 & 13,0 & 5,0 & 7,5 & 7,5 \\
\hline Laranja & - & 4,0 & 1,0 & 2,0 & - & - & 1,0 \\
\hline Manga & - & - & - & 2,0 & 4,0 & 2,0 & 1,5 \\
\hline Mamão & - & 1,0 & 2,0 & 1,0 & - & 2,0 & 1,0 \\
\hline Limão & 3,0 & - & 2,0 & 1,0 & - & - & 1,0 \\
\hline Outros & - & 3,0 & 1,0 & 4,0 & 1,0 & - & - \\
\hline
\end{tabular}


SILVA, R.R. da; SANTOS SPINELLI, M.A. dos; ALBUQUERQUE, M.C.W.; SANTOS, S.M.C. dos \& YOKOO, E.M. -- lndicadores das condiçðes nutricionais na Região do Polonoroeste. IV. Inquérito alimentar em famílias de seis cidades da Região do Polonoroeste, Mato Grosso, Brasil, 1983. Rev. Inst. Med. trop. Sào Paulo, 30(3):185-191, 1988.

TABELA 11

Referência ao consumo de Infusos e Bebidas: percentual médio em cada cidade e na Região - 1983.

\begin{tabular}{|c|c|c|c|c|c|c|c|}
\hline $\begin{array}{l}\text { Infusos } \\
\text { e } \\
\text { Bebidas }\end{array}$ & $\begin{array}{c}\text { Jauru } \\
\%\end{array}$ & $\begin{array}{c}\text { Araputanga } \\
\%\end{array}$ & $\begin{array}{c}\text { Mirassol } \\
\text { D'Oeste } \\
\%\end{array}$ & $\begin{array}{c}\text { Cáceres } \\
\%\end{array}$ & $\begin{array}{c}\text { Tangará } \\
\text { da Serra } \\
\%\end{array}$ & $\begin{array}{c}\text { Nova } \\
\text { Olímpia } \\
\%\end{array}$ & $\begin{array}{c}\text { Médio } \\
\text { Região } \\
\%\end{array}$ \\
\hline Café & 92,0 & 85,0 & 82,0 & 64,0 & 89,5 & 83,0 & 82,5 \\
\hline Chá mate & 3,0 & 9,5 & 16,0 & 31,0 & 14,5 & 7,5 & 13,5 \\
\hline Suco Artificial & - & 12,0 & 3,5 & 7,5 & 1,0 & - & 4,0 \\
\hline Refrigerantes & 3,0 & 1,0 & 1,0 & 2,0 & - & - & 1,0 \\
\hline Guaraná em Pó & - & - & - & 1,0 & - & - & 0,2 \\
\hline Outros & 3,0 & 1,0 & 1,0 & 1,0 & 1,0 & - & 1,0 \\
\hline
\end{tabular}

TABELA 12

Referência ao consumo de Produ tos Industrializados: percentual médio em cada cidade e na região - 1983.

\begin{tabular}{|c|c|c|c|c|c|c|c|}
\hline $\begin{array}{c}\text { Produtos } \\
\text { Industrializados }\end{array}$ & $\begin{array}{c}\text { Jauru } \\
\%\end{array}$ & $\begin{array}{c}\text { Araputanga } \\
\%\end{array}$ & $\begin{array}{c}\text { Mirassol } \\
\text { D'Oeste } \\
\%\end{array}$ & $\begin{array}{c}\text { Cáceres } \\
\%\end{array}$ & $\begin{array}{c}\text { Tangará } \\
\text { da Serra } \\
\%\end{array}$ & $\begin{array}{c}\text { Nova } \\
\text { Olímpia } \\
\%\end{array}$ & $\begin{array}{c}\text { Médio } \\
\text { Região } \\
\%\end{array}$ \\
\hline Achocolatados & 3,0 & 1,0 & 3,0 & 6,0 & 9,0 & 2,0 & 4,0 \\
\hline Maionese & - & 2,0 & 1,0 & 1,5 & 3,0 & - & 1,5 \\
\hline Cereais Pré-Cozidos & - & 1,0 & - & 1,0 & - & - & 0,3 \\
\hline Azeitona & - & - & 0,5 & 0,5 & 1,0 & - & 0,3 \\
\hline Ervilha & - & - & - & 0,5 & 2,0 & - & 0,4 \\
\hline Palmito & - & - & 0,5 & 0,5 & 1,5 & - & 0,4 \\
\hline Caldo de Carne & - & - & 0,5 & 0,5 & - & - & 0,2 \\
\hline Sorvete & - & - & - & - & 1,0 & - & 0,2 \\
\hline Massa Santista & - & - & - & 0,5 & - & - & 0,1 \\
\hline
\end{tabular}

TABELA 13

Referência ao consumo de Condimentos: percentual médio em cada cidade e na região - 1983.

\begin{tabular}{|c|c|c|c|c|c|c|c|}
\hline Condimento & $\begin{array}{c}\text { Jauru } \\
\%\end{array}$ & $\begin{array}{c}\text { Arapu tanga } \\
\%\end{array}$ & $\begin{array}{c}\text { Mirassol } \\
\text { D'Oeste } \\
\%\end{array}$ & $\begin{array}{c}\text { Cáceres } \\
\%\end{array}$ & $\begin{array}{c}\text { Tangará } \\
\text { da Serra } \\
\%\end{array}$ & $\begin{array}{c}\text { Nova } \\
\text { Olímpia } \\
\%\end{array}$ & $\begin{array}{c}\text { Médio } \\
\text { Região } \\
\%\end{array}$ \\
\hline Sal & 97,5 & 96,0 & 97,5 & 87,5 & 99,0 & 100,0 & 96,0 \\
\hline Alho & 78,5 & 68,0 & 74,0 & 61,0 & 84,5 & 87,0 & 75,5 \\
\hline Pimenta & 24,5 & 34,5 & 47,0 & 24,0 & 31,0 & 49,0 & 35,0 \\
\hline Vinagre & - & 14,0 & 13,0 & 14,0 & 12,5 & 7,5 & 10,0 \\
\hline Massa de Tomate & 13,5 & 7,5 & 4,5 & 3,5 & 11,5 & 5,5 & 7,5 \\
\hline $\begin{array}{l}\text { Fermento } \\
\text { Salsa/Cebolina e }\end{array}$ & 3,0 & 12,0 & 7,0 & 3,5 & 3,0 & 9,5 & 6,0 \\
\hline Coentro & 8,0 & 6,5 & 4,0 & 2,5 & 5,0 & 9,5 & 6,0 \\
\hline Arisco & - & 2,0 & - & 4,0 & 2,0 & - & 1,5 \\
\hline Colorau & 3,0 & 1,0 & 1,0 & 1,0 & 2,0 & - & 1,5 \\
\hline Outros & - & 2,0 & 1,0 & 1,5 & 2,0 & - & 1,0 \\
\hline
\end{tabular}

\section{RESULTADOS}

O levantamento sobre o consumo alimen- tar revelou os 15 alimentos mais referidos, representados na tabela 14.

Nas tabelas de 2 a 13 são apresentados os 
SIL. A. R.R. da; SANTOS SPINEI.LI, M.A. dos; AI.BLiQUERQUE, M.C.W.; SANTOS, S.M.C. dos \& YOKOO, E.M. - Indicadores das condiç̧es mutricionais na Regiāo do Polonoroeste. IV. Inquérito alimenıar em familias de seis cidades da Regiào do Polonoroeste, Mato Grosio, Brasil, 1983. Kev. Insi. Med. trop. São Paulo, 30(3):185-191, 1988.

\section{TABELA 14}

Os 15 alimentos mais referidos na região do Polonoroeste -1983.

\begin{tabular}{rlr}
\hline Ordem & Alimento & \% Referência \\
\hline 19 & Arroz & 99,5 \\
29 & Sal & 96,0 \\
39 & Feijão & 92,0 \\
49 & Açúcar & 87,0 \\
59 & Café & 82,5 \\
69 & Oleo Vegetal & 78,5 \\
79 & Alho & 75,5 \\
89 & Pão & 53,0 \\
99 & Carne Boi & 49,0 \\
109 & Cebola & 49,0 \\
119 & Tomate & 36,0 \\
129 & Pimenta & 35,0 \\
139 & Leite de Vaca & 31,0 \\
149 & Ovos & 24,5 \\
150 & Macarrão & 24,0 \\
\hline
\end{tabular}

resultados obtidos considerando os grupos de alimentos. Os dados são discriminados para cada cidade estudada e a média extrapolada para todas as cidades como um todo.

1) CEREAIS E DERIVADOS: nas famílias cstudadas o arroz é o cereal mais referido; ainda neste grupo foi referido o consumo do pão, do macarrão e da farinha de trigo.

2) LEGUMINOSAS: praticamente, só o feijảo foi referido.

3) RAÍZES, TUBÉRCULOS E DERIVADOS: predomina o consumo da batata inglesa, observa-se, no entanto, que os indices de referência ao consumo deste tubérculo são muito variáveis de uma cidade para outra, como extremos temos Jauru com $3,0 \%$ e Cáceres com $21,5 \%$.

4) CARNES: a carne bovina foi a mais referida seguida em niveis bem inferiores do peixe e do frango. Pode-se observar que o consumo da carne de boi variou muito de cidade para cidade, enquanto em Jauru atinge $30 \%$, em Cáceres chega a $60 \%$. Não se observou aumento do consumo de peixes onde o consumo de carne é menos referido, cmbora toda a regiào seja banhada por rios multo piscosos.

5) LEITE, DERIVADOS E OVOS: Arapuianga e Caceres revelaram indices mais altos de referencia a estes alimentos que as demais cidades. A média para a região de referência ao consumo do leite de vaca foi de $31,0 \%$ e de ovos, $24,5 \%$.
6) OLEOS E GORDURAS: o óleo vegetal é o alimento mais referido deste grupo.

7) AÇÚCARES: relevante assinalar apenas a referência ao consumo do açúcar refinado.

8) HORTALIÇAS: exceptuando-se a cebola, o tomate e a alface, as demais hortalicas tiveram índices de referência pouco significativos. Entretanto, o estudo revela que existe uma gama relativamente grande de hortaliças consumidas na região. Considerando as limitações de um estudo deste tipo, estes resultados podem estar mostrando que existe aí, o hábito de ingerir diversos tipos de hortaliças.

9) FRUTAS: a referência ao consumo de frutas foi insignificante, com exceção da banana, (considerando todos os tipos de banana). Não se sabe até que ponto o consumo de frutas não é referido, por elas serem, muitas vezes, ingeridas fora do horário das refeições, já que o estudo privilegia o consumo de alimentos por refeição. Esta observação é procedentc uma vez que observou-se em cidades como Cáceres um grande número de árvores frutíferas e intenso comércio de frutas nas ruas.

10) INFUSOS E BEBIDAS: café, chá/mate, suco artificial e guaraná de ralar foram os itens mais referidos neste grupo.

11) PRODUTOS INDUSTRIALIZADOS: a massa de tomate e os achocolatados foram os 2 produtos mais referidos embora em proporções de pequena significância.

12) CONDIMENTOS: conforme foi dito anteriormente, o sal, o alho e a pimenta figuram entre os mais referidos na região seguidos do vinagre e da salsa/cebolinha/ coentro.

\section{DISCUSS $\tilde{O}$}

$O$ estudo revela que os alimentos referidos nas entrevistas são alimentos básicos fontes de energia, semi-industrializados e de custo mais baixo.

Se da lista dos 15 alimentos mais referidos pelas familias forem excluidos o sal, o alho, a cebola e a pimenta (condimentos considerados como de baixo valor nutritivo), obteremos uma relaçào de alimentos muito semelhante aquela levantada em estudo realizado na periferia da cidade de Cuiabá, no mesmo ano, conforme demonstra o Quadro 1. 
SILVA, R.R. da; SANTOS SPINELLI, M.A. dos; ALBUQUERQUE, M.C.W.; SANTOS, S.M.C. dos \& YOKOO, E.M. - Indicadores das condiçðes nutricionais na Região do Polonoroeste. IV. Inquerito alimentar em familias de seis cidades da Região do Polonoroeste, Mato Grosso, Brasil, 1983. Rev. Inst. Med. trop. São Paulo, 30(3):185-191, 1988

\section{QUADRO}

Comparação entre os alimentos mais referidos em 2 inquéritos alimentares -1983 .

\begin{tabular}{|c|c|}
\hline $\begin{array}{l}\text { Alimentos mais } \\
\text { referidos na região do } \\
\text { Polonoroeste } / 1983^{1}\end{array}$ & $\begin{array}{l}\text { Alimentos mais } \\
\text { referidos na periferia de } \\
\text { Cuiabá } / 1983^{2}\end{array}$ \\
\hline 19 Arroz & 19 Arroz \\
\hline 29 Feijāo & 29 Feijão \\
\hline 30 Açúcar & 39 Açúcar \\
\hline 49 Café & 49 Oleo Vegetal \\
\hline 50 Oleo & 5ọ Café \\
\hline 69 Pão & 60 Carne Bovina \\
\hline 79 Carne Bovina & 7ọ Chá \\
\hline 80 Tomate & 8 Tomate \\
\hline 90 Leite de Vaca & 99 Leite de Vaca \\
\hline 10 Ovos & $10^{\circ}$ Massas \\
\hline 11 . Macarrão & \\
\hline
\end{tabular}

Fonte (1) - Inquérito Nutricional - Polonoroeste - 1983.

(2) - SILVA, R.R. et alii - Um estudo de caso sobre consumo de alimentos na periferia de Cuiabá - Cuiabá, MT, 1983 - Mimeo.

Como não se dispõe de dados sobre as quantidades consumidas não se pode traçar considerações a respeito da satisfação das necessidades nutricionais das pessoas. No entanto, pode-se afirmar que os alimentos mais referidos são os mesmos que estudos têm demonstrado em outras regiões do Brasil, como no ENDEF (Estudo Nacional da Despesa Familiar) realizado em todo o País pelo IBGE em $1974 / 75^{4}$

Uma observação mais detalhada destas informaçōes pode levar a considerações acerca da produção de alimentos. Sabe-se que na cidade de Araputanga existe uma indústria de laticínios e a referência do consumo destes produtos aí é mais elevada. O mesmo se pode dizer com relação ao consumo da carne bovina em Cáceres, região onde a pecuária é bastante difundida. A produção local pode ser um fator que influencie o consumo alimentar tanto pela disponibilidade no mercado como pelo custo mais acessivel. Associando-se as informações sobre os hábitos alimentares com as características que propiciem a produção de alimentos em ca- da região, pode-se incentivar a produção e o consumo de alimentos importantes e contribuir para o aumento da produtividade e da renda.

\section{SUMMARY}

Nutritional conditions indicators in Polonoroeste Area. IV - Food inquiry in families in 6 cities of Polonoroeste/MT Area, 1983

This work refers to collected data in a $24 \mathrm{~h}$ - oral - recall method, from the Nutritional Inquiry of Health Diagnostic Survey in Polonoroeste area in 1983, within six cities from this area.

As a first approach of the Nutritional problematic of the area, the study shows the most referred foods in the interviews, which are non industrialized basic foods, source of energy and of lower cost.

\section{REFERÊNCIAS BIBLIOGRÁFICAS}

1. MEIRELLES, S.M.P. - Adaptação do desenho amostral da Pesquisa em Saúde Pública no Polonoroeste/MT, 1984. (mimeografado)

2. UFMT - CCBS - Grupo de Pesquisa em Saúde no Polonoroeste - Pesquisa em Saúde Coletiva no Polonoroeste - 1. Pressupostos Gerais; 2. Pressupostos teórico-metodológicos; 3. Descrição do desenho da amostra - UFMT - CCBS - Grupo de Pesquisa Inquérito Nutricional. Cuiabá/MT, 1982. (mimeografado)

3. UFMT - CCBS - Grupo de Pesquisa Inquérito Nutricional - Pesquisa em Saúde Coletiva no Polonoroeste - Protocolo do Inquérito Nutricional. Cuiabá/MT, 1983. (mimeografado)

4. VIACAVA, F.; FIGUEIREDO, C.M.P. \& OLIVEIRA, W.A. - A desnutrição no Brasil: uma análise do Estudo Nacional da Defesa Familiar (IBGE 74/75) para o Nordeste, Estado de São Paulo e Estado do Rio de Janeiro. Petrópolis, Editora Vozes, 1983. 